\title{
Application of various approaches to modeling the gas emissions from TPP cleaning processes
}

\author{
Olesya Aksenova ${ }^{1 *}$, and Evgenia Nikolaeva ${ }^{1}$ \\ ${ }^{1}$ EDP Sciences, T.F. Gorbachev Kuzbass State Technical University, Underground Mining \\ Department, 650000 Kemerovo, 28 Vesennya st., Russian Federation
}

\begin{abstract}
The article discusses the possibility of 3D computer modeling tools complex use based on the mathematical processing of the gas emissions from TPP cleaning process. The authors propose to consider an approach to designing a site for capturing solid particles in gas emissions that appear during the production activities of an industrial enterprise by modeling a technological site in various programs. Mathematical processing with the use of the E-network device and the creation of a 3D model enables to plan a site for capturing solid particles in gas emissions, choose the appropriate technology and thereby ensure the ecological effect of both existing and projected power plants. The authors present the results of processing the technological process of gas purification at thermal power plants in terms of E-networks using mathematical processing in the Simulink application, which displays a device model from the standard units available in the program and performs the necessary calculations. 3D models of individual pieces of equipment selected on the basis of mathematical processing calculations in the Simulink application were created using computer $3 \mathrm{D}$ modeling in a graphical editor. A $3 \mathrm{D}$ visualization of the technological site for capturing solid particles in gas emissions was carried out, enabling a visual display of the planned site at the design stage, which, if necessary, will allow an easy introduction of modifications to the project.
\end{abstract}

\section{Introduction}

Today, the energy industry in Russia remains the basic industry. Many spheres of life are not possible without the products of thermal power plants (TPPs) operation. Without electricity, the work of the sectoral industry is also not possible.

According to statistical data, there are different types of power plants operating in our country. The most common are thermal power plants, the initial resource of which is combustible fuel, the combustion products of which lead to harmful emissions into the environment.

As a result of TPP operation, various combustion products are formed: fly ash, particles of unburned fuel, gases such as sulfurous-acid and sulfuric anhydride, nitrogen oxide, etc. Solid particles released as a part of harmful gas emissions are harmful to the environment

\footnotetext{
${ }^{*}$ Corresponding author: aka.gp061@,kuzstu.ru
} 
and public health. To purify gas emissions, physical principles allowing to separate solid particles from the flow of dusty gases are used [1].

At present various methods and technologies are used to purify gas emissions, for example, mechanical filtration, which is used wherever gases contain solid particles. The mechanical filtration work is based on the principles of gas mechanics, which includes multistage filtration on special devices with filters made of non-woven materials.

\section{Materials \& Methods}

Currently, the fuel industry is the basis for the development of the Russian economy. The task of the modeling the fuel and energy complex processes is considered relevant. In addition, the operation of such industries entails massive emissions of gases into the environment due to the products of coal combustion processing. Thus violating the environmental and industrial safety of the world around. Therefore, when planning and modeling the processes of fuel and energy complexes, it is necessary to provide for the availability of waste recycling systems, namely, a system of gas emissions cleaning, which will ensure environmental and industrial safety and will be economically efficient [2].

When designing the working processes of a TPP, there is currently a sufficient number of computer programs that enable to use different approaches in its future operation. Based on the results of mathematical modeling, the resulting model can be adjusted to improve it. At the next stage, it is advisable to use three-dimensional computer modeling, which allows to get a realistic image of individual pieces of equipment or the technological site as a whole, as well as to detect possible errors and make timely adjustments at the design stage. [3-5].

Mathematical modeling was performed using the E-networks device, which is used to model various systems [6].

The paper considers an abstracted model of a TPP with the possibility of expansion. (Fig. 1.)

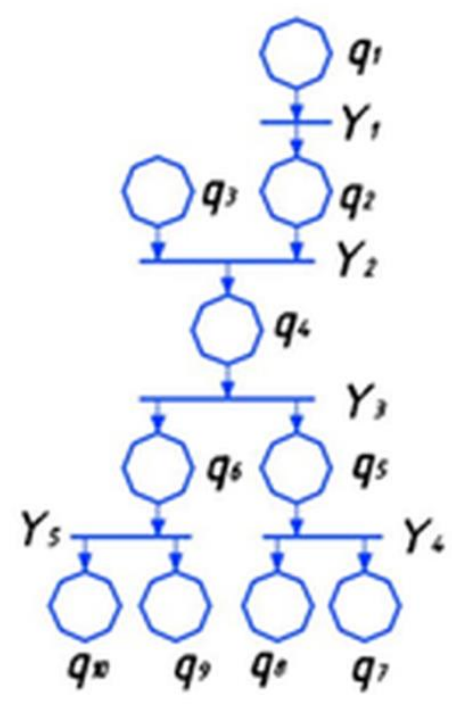

Fig. 1. TPP model in terms of E-networks 
Where $\mathrm{q}_{1}$ - coal delivered to the crushing plant; $\mathrm{q}_{2}$ - processed coal; $\mathrm{q}_{3}$ - condensate delivered to the storage; $\mathrm{q}_{4}$ - raw materials delivered to the combustion chamber; $\mathrm{q}_{5}-$ combustion products; $\mathrm{q}_{6}$ - steam supply to the turbine; $\mathrm{q}_{7}$ - ash and slag waste disposal; $\mathrm{q}_{8}$ - delivery of gaseous wastes to the purifying system; $\mathrm{q}_{9}$ - transmission of electricity in the power grid; $\mathrm{q}_{10}$ - steam removal;

$\mathrm{Y}_{1}=\left(\mathrm{T}, 0, \varphi_{1}\right)-$ coal processing;

$$
\varphi_{1}=L\left(Y_{1}\right)=\left\{q_{1} Y_{1} \mid Y_{1} \rightarrow q_{1} q_{2}\right\}=\left\{q_{1} q_{2}\right\}
$$

$\mathrm{Y}_{2}=\left(\mathrm{I}, 0, \varphi_{2}\right)$ - delivery of raw materials to the combustion chamber;

$\varphi_{2}=\mathrm{L}\left(\mathrm{Y}_{2}\right)=\left\{\mathrm{q}_{2} \mathrm{q}_{3} \mathrm{Y}_{2} \mid \mathrm{Y}_{2} \rightarrow \mathrm{q}_{2} \mathrm{q}_{3} \mathrm{q}_{4}\right\}=>L\left(\mathrm{Y}_{2}\right)=\left\{\mathrm{q}_{2} \mathrm{q}_{3} \mathrm{q}_{4}\right\}$,

$\mathrm{Y}_{3}=\left(\mathrm{F}, 0, \varphi_{3}\right)-$ processing of solid raw materials;

$\mathrm{Y}=\left(\mathrm{F}, 0, \varphi_{4}\right)-$ wastes removal;

$$
\varphi_{3}=\mathrm{L}\left(\mathrm{Y}_{3}\right)=\left\{\mathrm{q}_{4} \mathrm{Y}_{3} \mid \mathrm{Y}_{3} \rightarrow \mathrm{q}_{4} \mathrm{q}_{5} \mathrm{q}_{6}\right\}=\left\{\mathrm{q}_{4} \mathrm{q}_{5} \mathrm{q}_{6}\right\}
$$

$$
\varphi_{4}=\mathrm{L}\left(\mathrm{Y}_{4}\right)=\left\{\mathrm{q}_{5} \mathrm{Y}_{4} \mid \mathrm{Y}_{4} \rightarrow \mathrm{q}_{5} \mathrm{q}_{7} \mathrm{q}_{8}\right\}=\left\{\mathrm{q}_{5} \mathrm{q}_{7} \mathrm{q}_{8}\right\},
$$

$Y_{5}=\left(F, 0, \varphi_{5}\right)$ - electricity generation and steam removal;

initial marking: $(1,0,1,0,0,0,0,0,0,0)$.

$$
\varphi_{5}=L\left(\mathrm{Y}_{5}\right)=\left\{\mathrm{q}_{6} \mathrm{Y}_{5} \mid \mathrm{Y}_{5} \rightarrow \mathrm{q}_{6} \mathrm{q}_{9} \mathrm{q}_{10}\right\}=\left\{\mathrm{q}_{6} \mathrm{q}_{9} \mathrm{q}_{10}\right\},
$$

MatLab and its Simulink application were used to calculate the TPP parameters.

The Simulink application works on the principles of visual programming, the required model is built from the library of standard blocks, and then the necessary calculations can be made. When working with this application, you need to know the basic techniques of working in the Simulink environment and the task under study [7-10].

The model obtained using Simulink (Fig. 2) is a balance model of TPP material flows. It simulates the following technological stages:

1. preparation of solid fuel for combustion,

2. electricity generation,

3. formation and processing of ash and slag wastes,

4. formation and purification of gas emissions.

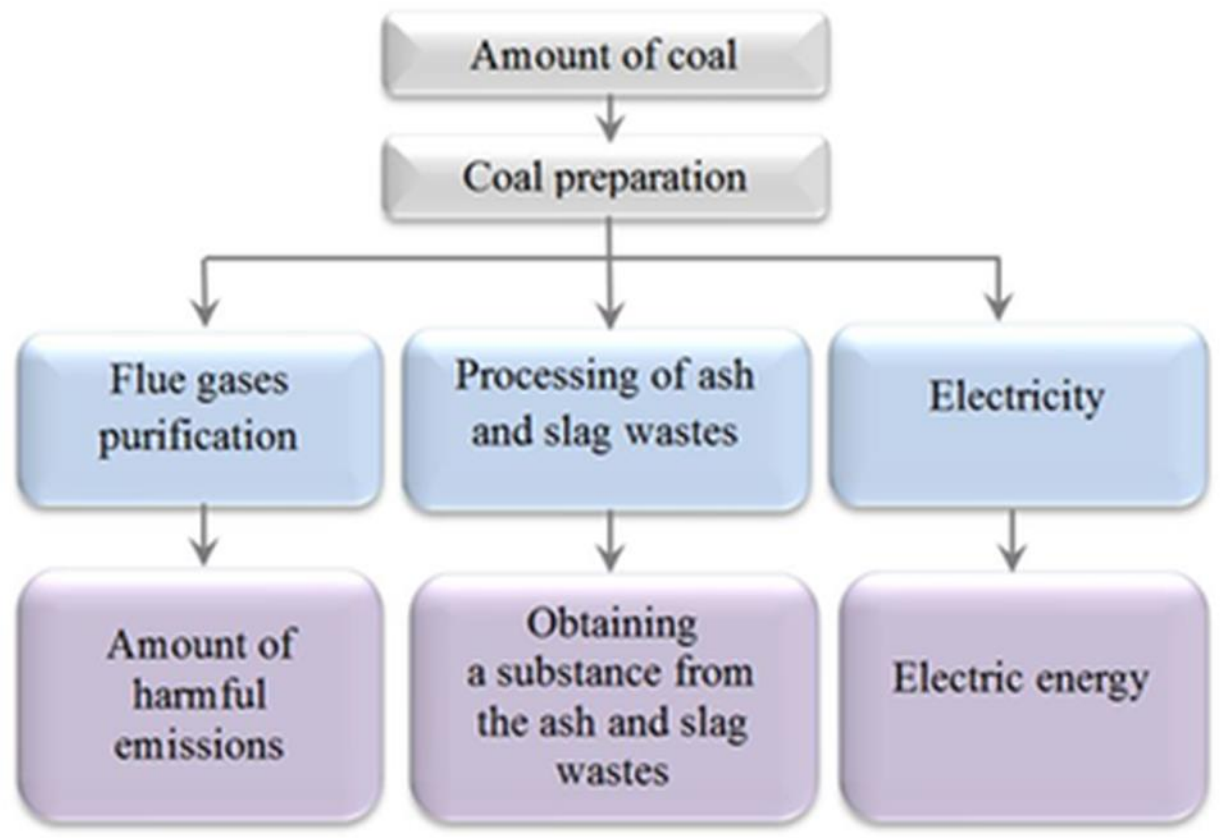

Fig. 2. Balance model of TPP material flows 
For the sake of clarity of the model and convenience of its expansion, the processing and purification units were implemented in the form of subsystems. Figure 3 shows the subsystem for purifying gas emissions from TPP, which in its turn also consists of several modules.

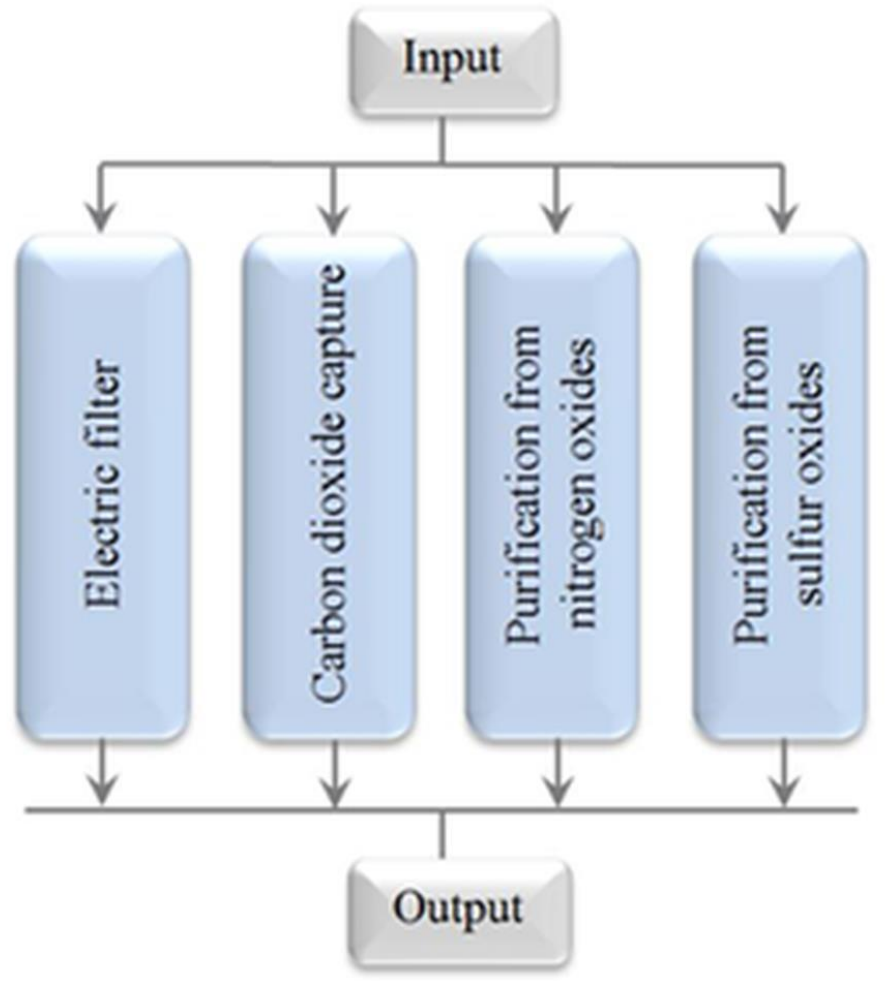

Fig. 3. TPP gas emissions purification subsystem

The first in the cycle of these modules is the electrofilter. When calculating its efficiency, the following formula was used:

$$
\mathrm{M}_{\mathrm{T}}=\mathrm{A} \cdot \mathrm{m} \cdot \chi \cdot\left(1-\frac{\eta_{\tau}}{100}\right)
$$

where $\mathrm{M}_{\mathrm{T}}$ - gross emission of solid particles in flue gases; $\mathrm{A}-$ fuel ash content, in \%; $\mathrm{m}-$ amount of fuel consumed per year, $\mathrm{t} ; \chi-$ the dimensionless coefficient that characterizes the proportion of fly ash carried away with flue gases, it depends on the type of furnace and fuel; $\eta_{\tau}-$ efficiency of ash collectors, $\%$.

Electric filters are currently widely used in TPP that use solid fuel as their source resource. This is a special electrical equipment using a corona discharge to capture particles suspended in the gas. The principle of operation of the electric filter is that gas emissions containing solid impurities pass through the electric field. In this case, the solid particles acquire a charge and are attracted to the collecting electrode, which has tubes and plates with the opposite charge. After that, their charge is neutralized and by rapping or water flushing, the solid particles fall into the hopper under the installation [11-15].

When designing the technological process of gas emissions, it is necessary to take into account the amount of gas emissions and their chemical composition, the physical characteristics of solid particles, as well as the required efficiency of the electric filter. An example of an electric filter with a standard design is shown in Figure 4. 

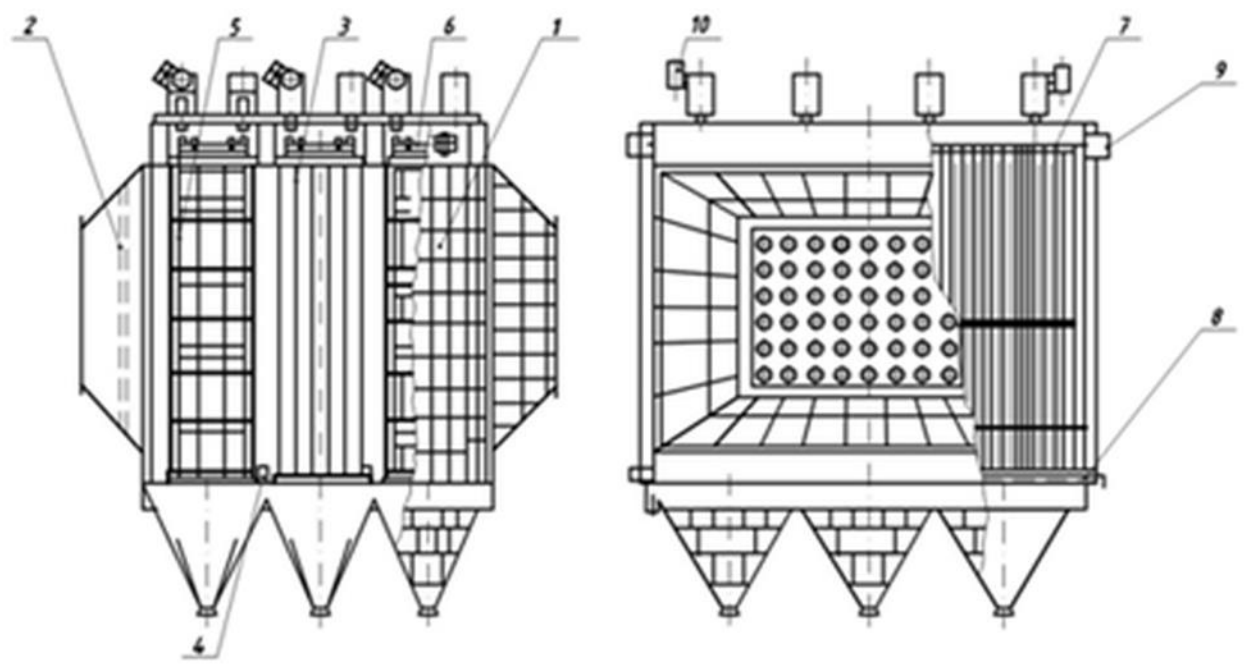

Fig. 4. The example of an electric filter with a standard design

1 - casing; 2 - gas distribution system; 3 -collecting electrodes; 4 - rapping mechanism of collecting electrodes; 5 -discharge electrodes; 6 - discharge electrodes suspension frame; 7 - discharge electrodes rapping mechanism; 8 -drive of the rapping mechanism of collecting electrodes; 9 - drive of the discharge electrodes rapping mechanism; 10 - current lead.

The model of the electric filter system in terms of E-networks can be represented in the following way:

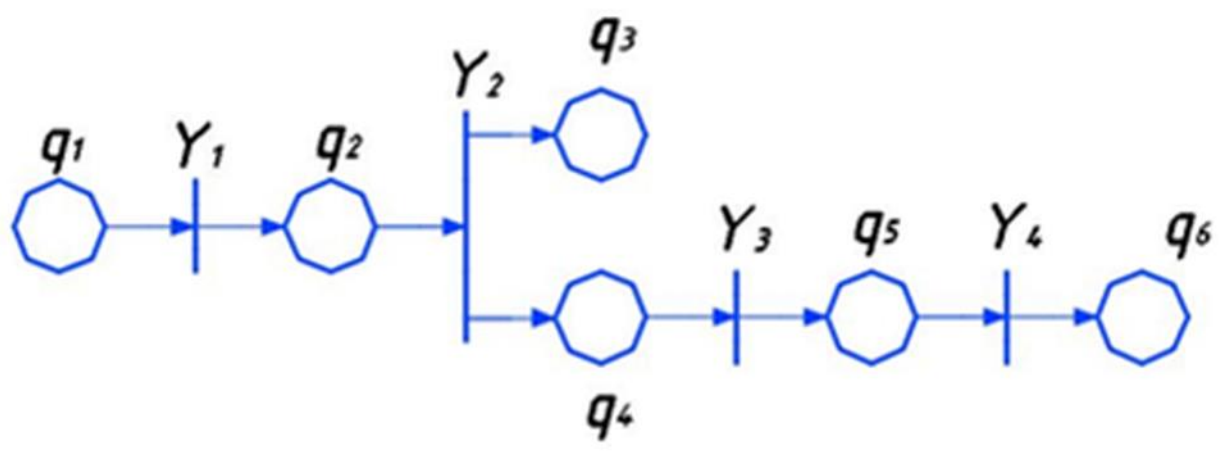

Fig. 5. Моде The model of the electrofilter system in terms of E-networks

Introduce the notation:

$q_{1}$ - flue gases get through the gas distribution grid to the corridors with grounded collecting electrodes;

$\mathrm{q}_{2}$ - charged gas particles under the influence of electric field forces move to the electrodes;

$\mathrm{q}_{3}$ - the purified air is removed from the installation;

$\mathrm{q}_{4}$ - charged ash particles are deposited on the collecting electrodes;

$\mathrm{q}_{5}$ - the filter cake (sediment on the filter) enters the scraper conveyor through the sluice valve;

$\mathrm{q}_{6}$ - the sediment is removed from the installation;

$\mathrm{Y}_{1}=\left(\mathrm{T}, 0, \varphi_{1}\right)-$ gas ionization process; 


$$
\begin{gathered}
\varphi_{1}=L\left(Y_{1}\right)=\left\{q_{1} Y_{1} \mid Y_{1} \rightarrow q_{1} q_{2}\right\}=\left\{q_{1} q_{2}\right\} \\
Y_{2}=\left(F, 0, \varphi_{2}\right)-\text { deposition of particles on the electrodes; } \\
\varphi_{2}=L\left(Y_{2}\right)=\left\{q_{2} Y_{2} \mid Y_{2} \rightarrow q_{2} q_{3} q_{4}\right\}=\left\{q_{2} q_{3} q_{4}\right\} \\
Y_{3}=\left(T, 0, \varphi_{3}\right)-\text { the rapping process; } \\
\varphi_{3}=L\left(Y_{3}\right)=\left\{q_{4} Y_{4} \mid Y_{4} \rightarrow q_{4} q_{5}\right\}=\left\{q_{4} q_{5}\right\} \\
Y_{4}=\left(T, 0, \varphi_{4}\right)-\text { the process of removing sediment from the installation. } \\
\varphi_{4}=L\left(Y_{4}\right)=\left\{q_{5} Y_{4} \mid Y_{4} \rightarrow q_{5} q_{6}\right\}=\left\{q_{5} q_{6}\right\} .
\end{gathered}
$$

\section{Results \& Discussion}

When modeling in the Simulink environment, it is important that all the units can be selected from the library and based on them, one can create the necessary model and perform calculations. These principles of visual programming enable not to learn programming languages and numerical methods of mathematics, but simply use them as built-in tools. Being a specialist in one's subject area, one can easily assess the correctness of the calculations obtained.

The model obtained in the Simulink environment is a balance model of material flows $[6,7]$, which includes several technological stages: preparation of solid fuel; generation of electricity; formation and processing of ash and slag wastes; formation and purification of gas emissions. The balance model is implemented in the form of subsystems. Next, the paper presents an example of modeling the subsystem for capturing solid particles in gas emissions.

Building a spatial model of an object makes it possible to get a visual image of the object under study. Creating a realistic image based on this image enables to get a visualized project and evaluate possible technical defects in the planning of technological sites, and timely eliminate them with minimal economic costs.

The work on creating solid-state models and the visualization process can be divided into several sequential operations: building 3D models, applying textures onto them, getting animation, rendering.

At the initial stage, according to the available graphic documentation, solid-state models of the equipment units included in the technological line of the technological process for capturing solid particles in gas emissions are obtained using the tools of the graphic editor. An example of constructing a solid-state model of an electrofilter used for the deposition of gas emissions solid particles is shown in Figure 5.

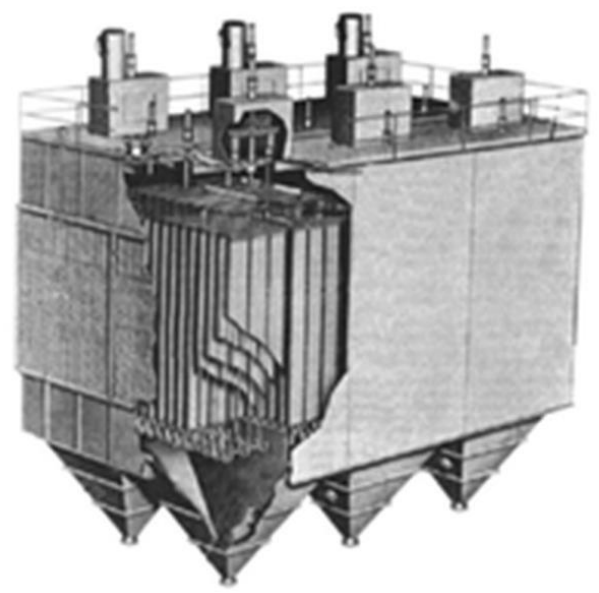

Fig. 6. Solid-state model of the electrofilter 
Then, using the graphic editor, from the solid-state models of equipment involved in the technological process of capturing solid particles in gas emissions, a technological site is planned on the production site, taking into account the arrangement of equipment according to technological requirements. An example of a technological site for capturing solid particles in gas emissions is shown in Figure 7.
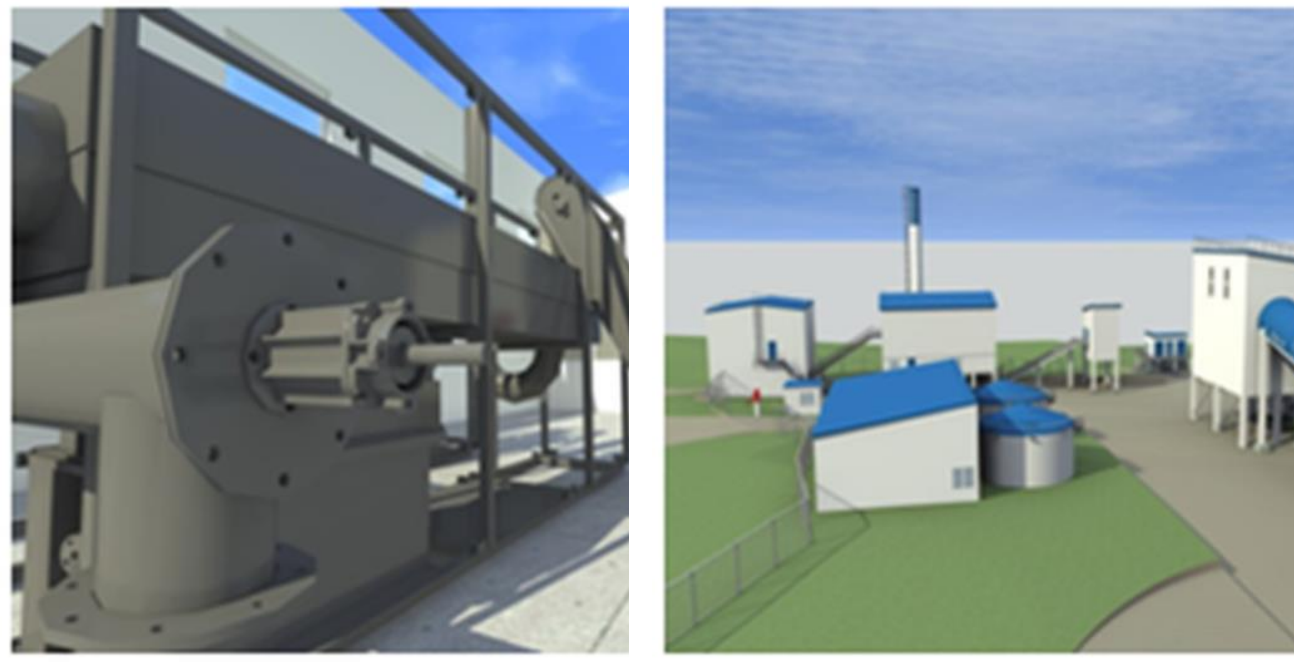

Fig. 7. Three-dimensional model of the technological site for capturing solid particles in gas emissions

It should also be noted that the resulting model can be further expanded by adding the necessary modules to its structure.

\section{Conclusions}

This paper presents the possibility of applying different approaches to modeling the processes of TPP gas emissions purification. To solve this problem, CAE and CAD systems were used to simulate the technological process of capturing solid particles in gas emissions. Optimization of the solid particles capture system planning by means of mathematical processing and computer modeling is proposed, which can allow to evaluate the planned result, to identify the most suitable technology for purifying gas emissions. The paper presents the results of processing the planned technological processes of the system for capturing solid particles in gas emissions in terms of E-networks using the Simulink application. A three-dimensional model of the specified technological process is also presented, on its basis it is possible to give a preliminary assessment of the future production site in terms of the effectiveness of the selected equipment units, and, if necessary, to make changes to the project at the planning stage. In addition, this approach can be applied to the TPP in operation.

\section{References}

1. O. Aksenova, E. Nikolaeva, E3S Web of Conferences, 41 (2018)

2. A. Kovalchuk, M. Klopot, Energy: economy, technology, ecology, 3 (37), 97 (2014)

3. V. E. Kotov, The main edition of the physical and mathematical literature, (Nauka, Moscow, 1984) 
4. N.N. Lychkina, Simulation modeling of economic processes: a tutorial, (NITs Infra-M, Moscow, 2014)

5. S.A. Mukhsin, Radio-engineering, 155, 159 (2008)

6. K.E. Plohotnikov, Computational methods. Theory and practice in MATLAB (+ file). (Hotline-Telecom, Moscow, 2013)

7. J. Kepner, Parallel programming in MATLAB environment for multicore and multilevel computers, (Moscow University Publishing House, Moscow, 2013)

8. Yu.F. Lazarev, Beginnings of programming in the MatLAB environment: a tutorial, (NTUU “KPI”, Kiev, 2003)

9. I.E. Fedotov, Parallel programming models (Solon-press, Moscow, 2012)

10. S.P. Bakhaeva, V.A. Gogolin, I.A. Ermakova, Journal of Mining Science, 52, 3, 454 (2016)

11. G.A. Kazunina, D.V. Alekseev, Advanced Materials Research, 933, 62 (2014)

12. Morad Behandish, Computer-Aided Design, 70, 100 (2016)

13. Wenlan Ba, NingRen, Lixin Cao, Graphical Models, 82, 1 (2015)

14. Hao Yang, Hui Zhang, Computers \& Graphics, 65, 45 (2017)

15. V.M. Zolotukhin, V.A. Gogolin, M.Yu. Yazevich, M.I. Baumgarten, A.V. Dyagileva, IOP Conference Series: Earth and Environmental Science, 50, 1, 012027 (2017) 